Mag. Daniela

Brečko,

GV Izobraže-

vanje, d.o.o.

\section{KONSTRUKTIVNI PRISTOP K NAČRTOVANJU OSEBNE KARIERE}

\title{
POVZETEK
}

Avtorica v prispevku predstavi pomen izobraževanja za konstruktivno načrtovanje kariere. Ugotavlja, da obstaja paleta formalnih in neformalnih izobraževalnih priložnosti, kjer lahko pridobimo znanje za konstruktivno načrtovanje kariere. Predstavi štiristopenjski model načrtovanja osebne kariere, ki sestoji iz diagnosticiranja, doseganja samouvida, izbiranja odločitve ter presojanja učinkovitosti odločitve. Opozori na nujnost proaktivnega odzivanja na spremembe in predstavi konkretne izobraževalne oblike, ki so nam lahko y pomoč pri načrtovanju oz. redefiniranju kariere. Temelj uspešnega načrtovanja kariere pa je predvsem dobro poznavanje sebe, zato avtorica predstavi ocenjevalni center kot instrument objektivnega vpogleda v lastne prednosti in pomanjkljivosti. Prav tako pa predstavi tudi alternativne izobraževalne vire za konstruktivno načrtovanje kariere, ki postajajo vse bolj popularni v novi ekonomiji.

Ključne besede: načrtovanje kariere, izobraževanje, nova ekonomija

$\mathbf{Z}$ uspešen razvoj osebne kariere je zelo pomembno, da si posameznik pridobi dovolj znanja za reševanje vsakokratnih problemov

\section{Za konstruktivno načrtovanje osebne kariere potrebujemo znanje.} in za konstruktivno obvladovanje teh življenjskih nalog. Posebnega izobraževalnega programa za načrtovanje osebne kariere ni, čeprav bi bil zelo dobrodošel oz. potreben in bi ga, kot smo to že omenili, bilo potrebno umestiti že $v$ redne oblike izobraževanja. Dejstvo namreč je, da za konstruktivno načrtovanje osebne kariere potrebujemo znanje.
V nadaljevanju se bomo posvetili vprašanju, kako lahko posameznik konstruktivneje pristopa $k$ reševanju te naloge. Predlagane možnosti temeljijo predvsem na opazovanju uspešnih posameznikov in poglobljenih intervjujev $\mathrm{z}$ njimi. Pri tem izhajam iz osnovnega izhodiš̌ča, da je razvoj osebnosti vseživljenjski proces in da se torej ne zaključi $v$ obdobju adolescence, kot to poudarjajo nekatere starejše teorije osebnosti, med njimi tudi Freudova psihoanalitična teorija.

Model konstruktivnega načrtovanja osebne kariere, ki ga predstavljam, je lahko tudi temelj in vir izobraževalnih potreb posa- 
meznika, ki se je znašel v danem procesu, in izvrstna podlaga za programiranje izobraževalnega programa. V zgodnjem obdobju procesa načrtovanja osebne kariere bi namreč moral posegati po tistih izobraževalnih vsebinah in razvijati tiste spretnosti, ki bi mu omogočile prepoznati problem, imeti uvid v samega sebe in izbrati pravi način za reševanje konkretnega problema. In ne le v zgodnejših obdobjih, tudi kasneje, ko se pojavi na razpotju oz. ko se pojavi potreba po redefiniranju karierne usmeritve.

\section{ŠTIRISTOPENISKI MODEL NACRTOVANJA OSEBNE KARIERE}

Konstruktivno načrtovanje osebne kariere predstavlja proces in nikakor ni enkratni dogodek - enkratna odločitev za posameznika. Vsakič, ko se znajdemo na razpotju, lahko sledimo skorajda do potankosti enakemu zaporedju faz. Proces, ki ga sestavljajo štiri glavne stopnje, predstavlja uspešen model reševanja problemov, kar navsezadnje načrtovanje osebne kariere tudi je:

\section{Prepoznavanje in diagnosticiranje} problema - izboljšati lastno razumevanje situacije, iz katere izhaja problem.

2. Doseganje globljega samouvida prepoznati svoje zmožnosti, omejitve, potrebe in občutke $v$ dani situaciji, skratka bolje spoznati sebe.

3. Izbiranje pravilne odločitve - kako se bomo odzvali na problem, ki nam v danem trenutku predstavlja izvor stresa.

4. Presojanje učinkovitosti odločitve / rešitve - evalvacija odziva na problem, kjer se sprašujemo, če smo ubrali pravo pot reševanja, smo se sploh soočili s problemom, smo problem rešili ...

\section{Prepoznavanje in diagnosti- ciranje problema}

Življenjske naloge, ki izhajajo iz kariernega



cikla, postavljajo pred posameznika veliko različnih potencialnih problemov, Za diagnosticiranje problema pa se je treba najprej vprašati,

- kaj je izvor problema,

- kakšna je stopnja težavnosti in

- zakaj je problem težak ter kako se na problem notranje odzovemo.

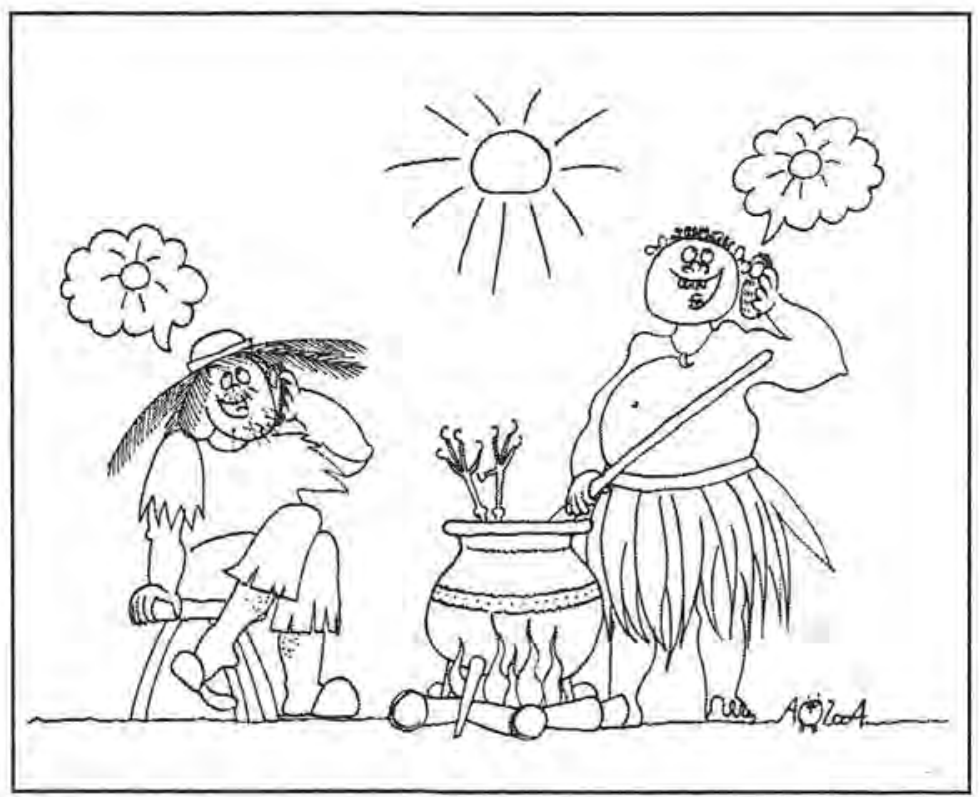


Ko se srečamo s problemom, gre ponavadi za tipično soočenje s potrebo po spreminjanju. Morda ne uživamo $v$ delu, tako kot smo si

Soočenje s problemom je hkrati tudi soocenjes potrebo po spreminjanju. zamislili, morda smo načrtovali zamenjavo službe, pa ugotovili, da je prehod iz enega okolja $v$ drugega težavnejši, kot smo pričakovali, ali pa želi naš partner nadaljevati prekinjeno šolanje, in to zahteva popolno reorganizacijo družinskega

življenja in prekinitev rutine $\mathrm{v}$ dnevnem opravljanju hišnih opravil. Z drugimi besedami, problem se pojavi vedno takrat, ko je prekinjen ustaljeni dnevni ritem, bodisi zaradi zunanjih dogodkov bodisi zaradi našega notranjega odziva oz. notranjih sprememb in pogledov na življenje. Najprej pa je zagotovo treba raziskati, odkod problem sploh prihaja. Kje je torej izvor stresa?

Tega ni mogoče enostavno odkriti, še posebej če vemo, da sta posameznikova samopredstava in kariera tesno povezani in gre med njima za močno interakcijo, ki se odraža na veliko različnih načinov. Zato ni vedno očitno, odkod problem izvira. Lahko, da je kdo razočaran, ker $v$ poklicni karieri ni napredoval in želi zamenjati službo, toda z globljo samoanalizo se izkaže, da je z delom povsem zadovoljen, pravi problem pa se skriva povsem drugje, recimo $v$ tem, da otroci odraščajo, se gredo šolat v drug kraj in zato potrebuje več denarja. $\mathrm{Za}$ konstruktivno reševanje življenjskih nalog je torej najprej treba določiti področje, odkoder problem izvira, bodisi iz zasebnega ali poklicnega življenja. C̆e v določenem obdobju na primer odkrijemo, da smo potrti, utrujeni in depresivni, se je treba vprašati, ali ta občutek izvira iz poklicnega življenja ali osebnih čustvenih razpoloženj. Vsekakor lahko predpostavimo, da je reševanje problema veliko težje, če je vpletenih več življenjskih področij.

Ključ za identifikacijo problema je skrbno opazovanje notranjih reakcij ter občutkov, ki jih sprožajo zunanji dogodki. Problema nismo diagnosticirali vse dotlej, dokler nismo raziskali, kako deluje na nas, kako se nanj odzivamo, kaj to pomeni za našo samopredstavo.

$\mathrm{Za}$ vsako reševanje problema pa seveda potrebujemo novo znanje ali sposobnosti in težavnost problema lahko ravno na tej podlagi tudi merimo. Če problem zahteva nove vzorce vedenja, $\mathrm{ki}$ jih posameznikove kognitivne sheme še niso osvojile, je reševanje takšnega problema veliko težje, kajti naučiti se povsem novíh stvari je zahtevnejše, kot da se na problem odzovemo $\mathrm{s}$ "starimi navadami". V kariernem ciklu so tako najtežji problemi povezani $\mathrm{z}$ vertikalnimi ali lateralnimi premiki, ko posameznik popolnoma zamenja poklic, kar zahteva ogromno novega učenja. Ali pa premik iz enega geografskega okolja $\mathrm{y}$ drugega, kar se dogaja vse pogosteje. Na prostem trgu delovne sile Evropske unije se odpira veliko novih priložnosti, ki zahtevajo tudi geografske premike. Prav tako lahko veliko problemov povzroči sprememba dela, kar se tudi vse pogosteje dogaja. Posameznik, ki je leta delal določeno delo na ustaljeni

Pomanjkanje znanja na področju načrtovanja karier je morda najbolj očitno pri prehodu študentov v poklicno življenje. Nemalo primerov je, ko uspešni študentje nikakor ne morejo zaključiti študija, manjka jim morda le izpit ali dva. Skoraj zagotovo ne gre za težavnost izpitov, saj bi se to izkazalo že prej, med študijem, ampak predvsem za neodločenost glede poklicne izbire in strah pred zamenjavo socialnega statusa - iz statusa študenta $v$ status odrasle osebe s polno materialno in socialno odgovornostjo. 
način, se mora čez noč naučiti povsem novih, sodobnejšsih metod dela. Spremembe delovne skupine zahtevajo učenje nove kulture, zamenjava šefa zahteva, da se naučimo novih odzivov.

Težavnost problema lahko merimo tudi po tem, koliko energije in zbranosti terja od nas. Problemi, povezani $\mathrm{z}$ medosebnimi odnosi tako na delovnem mestu kot doma, so veliko težji, ker zahtevajo stalno zbranost in polno vpletenost ter so zelo dolgotrajni. Odnose lahko gradimo leta, podremo pa jih lahko $\mathrm{z}$ enim samim dejanjem. Brez poznavanja izvora problema ne moremo iskati poti za njegovo reševanje, oziroma se lahko odločamo le po trenutnih vzgibih.

$\mathrm{Za}$ diagnosticiranje problema je treba vedeti tudi, kako problem vpliva na nas oz. kakšne reakcije izzove. Mnogi ljudje so prepričani, da dobro vedo, kaj je vir njihovega problema, manj pa se zavedajo, kako se sami odzivajo na problem. Za konstruktivno reševanje problemov je nadvse pomembno, da ima posameznik globok uvid vase, se zaveda svojih pomanjkljivosti in dobrih lastnosti, da si prizna lastne napake, se pri odzivanju na problemsko situacijo čustveno obvladuje ...

\section{Doseganje globljega samouvida}

Samouvid ni nekaj, kar bi ljudje dosegli avtomatično $\mathrm{z}$ bogatenjem izkušenj. Samouvid lahko dosežemo le skozi sistematično samoopazovanje in prizadevanje razumeti, kaj se dogaja v nas ob različnih problemskih situacijah. Izobraževalni programi s področja osebnostnega razvoja, transakcijske analize in podobni so dobrodošli, ker predstavljajo proces časovno določenega in načrtnega samospoznavanja, v katerem se posamezniki sprijaznijo s samim seboj. Znani geografski raziskovalec Livingston je nekoč dejal, da je soočenje s samim seboj lahko hujše kot smrt. Najtežji del učenja o sebi predstavlja prepo- znavanje in zavedanje lastnih občutkov in učenje o tem, kaj jih sproža. Če nam pri vožnji $\mathrm{z}$ avtomobilom nekdo nenadoma prečka pot, postanemo jezni in začnemo $z$ njim tekmovati. In čeprav je težko sprejeti dejstvo, je to vedno naša zavestna odločitev. V predstavljenem primeru smo povsem sami izbrali čustvo jeze, najbrž tudi zato, ker jo do določene stopnje čutimo pač kot pozitivno, navdaja nas $z$ večjo (lažno) fizično močjo; $v$ primerjavi $z$ depresijo ali žalostjo se ljudje zagotơvo bolje počutimo, kadar smo jezni. Toda s tem spravljamo sebe in sopotnike v nevarno situacijo in lahko le sebe krivimo za morebitno prometno nesrečo. Isto bi lahko prenesli na področje medosebnih odnosov. Ce nas $v$ pogovoru kdo grobo prekine, zopet izbiramo, ali bomo dali duška besu ali pa reagirali na bolj umirjen način. Če smo se odločili za prvo izbiro, potem smo pravzaprav mi želeli prepir.

\section{Izbiranje pravilne odločitve}

Odgovor na reševanje problema predstavlja vse, kar posameznik naredi, da bi se problem razrešil. Ta odgovor je lahko tudi to, da posameznik nič ne naredi in pusti situacijo takšno, kot je, podobno kot se odloči, ali ga bo določena situacija vznemirila ali ne. Posameznik se lahko zateče k staremu odzivu ali pa se odzove na popolnoma nov način. Vendarle pa določene situacije od nas terjajo popolnoma nov odziv. V 90 -ih letih prejšnjega stoletja, ko se je množično odpuščalo

Dober učni primer samouvida je igra, kjer posameznik izgubi. S podrobnejšo analizo ljudje počasi odkrivajo, da velikokrat reagirajo na podlagi lastnih obrambnih mehanizmov; zanikajo, kar se je $v$ resnici zgodilo, krivijo druge za svoj neuspeh ali pa krivijo le sebe in se postavijo $v$ vlogo žrtve. Vsi trije obrambni mehanizmi zavirajo proces reševanja problemov. 
Zelo pomemben vidik iskanja pravilne rešitve oz. odziva na problem je v prvi vrsti globlji samouvid ter socialna interakcija $\mathrm{z}$ drugimi, ki predstavlja neke vrste oporo, je izvor motivacije in nam daje drugačno perspektivo oz. pogled na problem. Še posebej se bogato socialno okolje izven poklicnega življenja priporoča za menedžerje oz. vse tiste, ki načrtujejo kariero na vodilnih in vodstvenih položajih. Praviloma za njih velja, da ne morejo deliti svojih težav z zaposlenimi, saj na takšen način težje vzdržujejo nujno potrebno avtoriteto, zato pa je nujno, da imajo ljudi, ki jim lahko zaupajo svoje težave in hkrati preverjajo ustreznost odloěitve izven delovnega okolja.

tehnični kader in se je veliko inženirjev znašlo na cesti, so se ti zatekli $k$ tradicionalnemu odzivu. Iskali so službo v istem poklicu v drugih podjetjih. Šele v posebnih izobraževalnih programih za prestrukturiranje brezposelnih so počasi premislili svojo situacijo, samopredstavo so širše redefinirali, ne le na podlagi poklicne vloge, in pridobili nova znanja ter spretnosti, ki so jim omogočali vrnitev na trg delovne sile.

Razvoj novega odziva na situacijo zahteva določeno pomoč drugih. Odgovor na mnogo vprašanj bomo morebiti našli v pogovoru s prijatelji, znanci, družino, sodelavci, ker se bomo ob tem naučili, kako problem vidijo oni in kako so ga reševali.

Drug pristop za izbiro pravilne odločitve pa predstavljajo organizirane delovne skupine, kjer se pod vodstvom mentorja vodijo pogovori in izmenjava izkušenj med udeleženci. Takšne skupine so praviloma majhne in ne

\section{Štiristopenjski model reševanja kariernih vprašanj}

Prepoznavanje in diagnosticiranje problema

$$
\checkmark
$$

Doseganje globljega samouvida

Izbiranje pravilne odIočitve

Presojanje učinkovitosti rešitve štejejo več kot pet ljudi, sicer intenzivna izmenjava izkušenj ni mogoča. Tovrstne skupine se $\mathrm{v}$ mnogih primerih organizirajo na zavodih za zaposlovanje za iskalce zaposlitve. Vsekakor pa so pogovori v skupini primerni tudi za reševanje drugih problemov, ne le za iskanje (nove) zaposlitve. Ta metoda je zelo učinkovita tudi pri reševanju s kariero povezanih problemov, na primer kako bolje uravnotežiti poklicno in zasebno življenje, kako načrtovati kariero, odkar so otroci odšli od doma in je na voljo več časa, kako sodelovati z različnimi tipi direktorjev.

Oboje je torej potrebno, tako samouvid kot tudi pomoč drugih. Tako se kažejo sposobnosti za razvoj globljega samouvida ter tudi spretnosti in sposobnosti vzpostavljanja dolgoročnih odnosov z drugimi več kot nujne za konstruktivno reševanje kariernih vprašanj. Sposobnost aktivnega poslušanja, prepoznavanja lastnih čustvenih stanj. samorefleksije, sposobnost zaupati se neko$\mathrm{mu}$, sposobnost samonadzora ... vse to je izjemno pomembno za reševanje problemov na vseh področjih življenja.

Problem smo dokončno rešili šele, ko smo preverili tudi, ali je bila naša pot reševanja problema prava ali smo ga le preložili na kasnejše obdobje. Uspešno upravljanje problema je pravzaprav ciklični proces reševanja problema, ki se začne $\mathrm{z}$ identifikacijo, nadaljuje $\mathrm{z}$ akcijo, rezultat te akcije pa nas vodi v novo fazo identifikacije. $S$ to povratno zanko smo se veliko naučili o naravi problema in dobili globlji vpogled vase. 


\section{KONSTRUKTIVNI PRISTOP K NAČRTOVANJU KARIERE ZAHTEVA UPRAVLIANJE SPREMEMB}

Delo se spreminja z veliko naglico. Še nikoli doslej spremembe niso bile tako velike in tako hitre kot prav $v$ informacijski družbi. Danes smo ljudje bolj kot kdajkoli prej izpostavljeni nenehnim spremembam delovnega okolja, ki nas venomer sili, da se spreminjamo in prilagajamo svoje vedenje novim zahtevam. Sprememb v človekovem ravnanju in delovanju seveda ne zahteva le današnji trenutek, spreminjali so se ljudje tudi v prejšnjih zgodovinskih obdobjih, le da takrat spremembe delovnega okolja niso bile tako velike in se niso vrstile s tolikšno naglico, kot smo ji lahko priča danes.

Potrebo po spreminjanju lahko ponazorimo s preprostim diagramom:

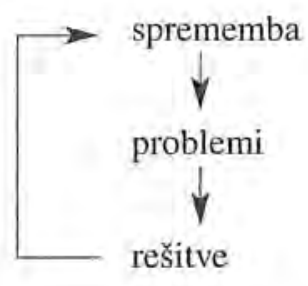

Spremembe okolja so danes tako hitre, da nekateri ljudje enostavno ne zmorejo z njimi v korak, Ne le na mikroravni (na ravni posameznika), temveč tudi na makroravni prihaja do enakega pojava. Družbe, ki imajo zelo visoko stopnjo sprememb, imajo praviloma tudi zelo veliko število brezposelnih. Njihove nesreče pa ne gre iskati $\mathrm{v}$ pomanjkanju delovnih mest, temveč $\mathrm{v}$ preskromni fleksibilnosti. Kadar se gospodarstvo in ekonomija izredno hitro spreminjata, mnogi ljudje, predvsem nižje izobraženi in socialno deprimirani, tega razvoja ne morejo dohitevati. $\mathrm{V}$ novo nastalih razmerah, $\mathrm{ki}$ jih povzročajo spremembe, niso več sposobni uspešno delovati, zato se enostavno vdajo in
Večina ljudi ne želi spreminjati svojega vedenja kar tako, ampak to od njih terjajo spremembe $v$ (delovnem) okolju. Ljudje se najhitreje spreminjajo, če se spremeni okolje, $v$ katerem delajo in živijo ter mu pripadajo. Svet pa se spreminja $v$ fizičnem, družbeno-socialnem in ekonomsko-gospodarskem smislu. Vse te spremembe povzročajo probleme in če se želimo spremembam prilagoditi, jih torej obvladovati, smo prisiljeni nenehno reševati probleme.

skrb zase naložijo družbi in svojemu ožjemu socialnemu okolju. Zakaj je v Združenih državah, ki veljajo za najbogatejšo deželo na svetu, toliko brezposelnih? Prav zato, ker so Združene države dežela $\mathrm{z}$ najvišjo stopnjo družbenih sprememb. Enako velja tudi za dežele v razvoju. V državah, ki se hitro industrializirajo, so ulice polne beračev. Še manj spodbudno sliko lahko napovemo za tako imenovano poindustrijsko obdobje, kjer od proizvodnih in storitvenih panog prehajamo na področja, ki temeljijo na znanju. Ta zahtevajo več možganov in manj mišic, čemur se nekateri ljudje ne morejo prilagoditi. (Brečko, 1998)

\section{PROAKTIVNO ALI PASIVNO ODZIVANJE NA SPREMEMBE}

Za učinkovito načrtovanje kariere bi se ljudje morali usposobiti predvsem za proaktivno obvladovanje in doživljanje sprememb. Pegg (1990) je skušal ponazoriti, skozi katere faze gre človek pri soočenju s spremembo, in je opredelil značilnosti reaktivnega in proaktivnega odnosa do sprememb.

Ljudje, ki se reaktivno odzivajo na spremembe, gredo skozi zelo težavno krivuljo. Ob spremembi najprej doživijo šok in poskušajo zanikati, da se je karkoli spremenilo, 


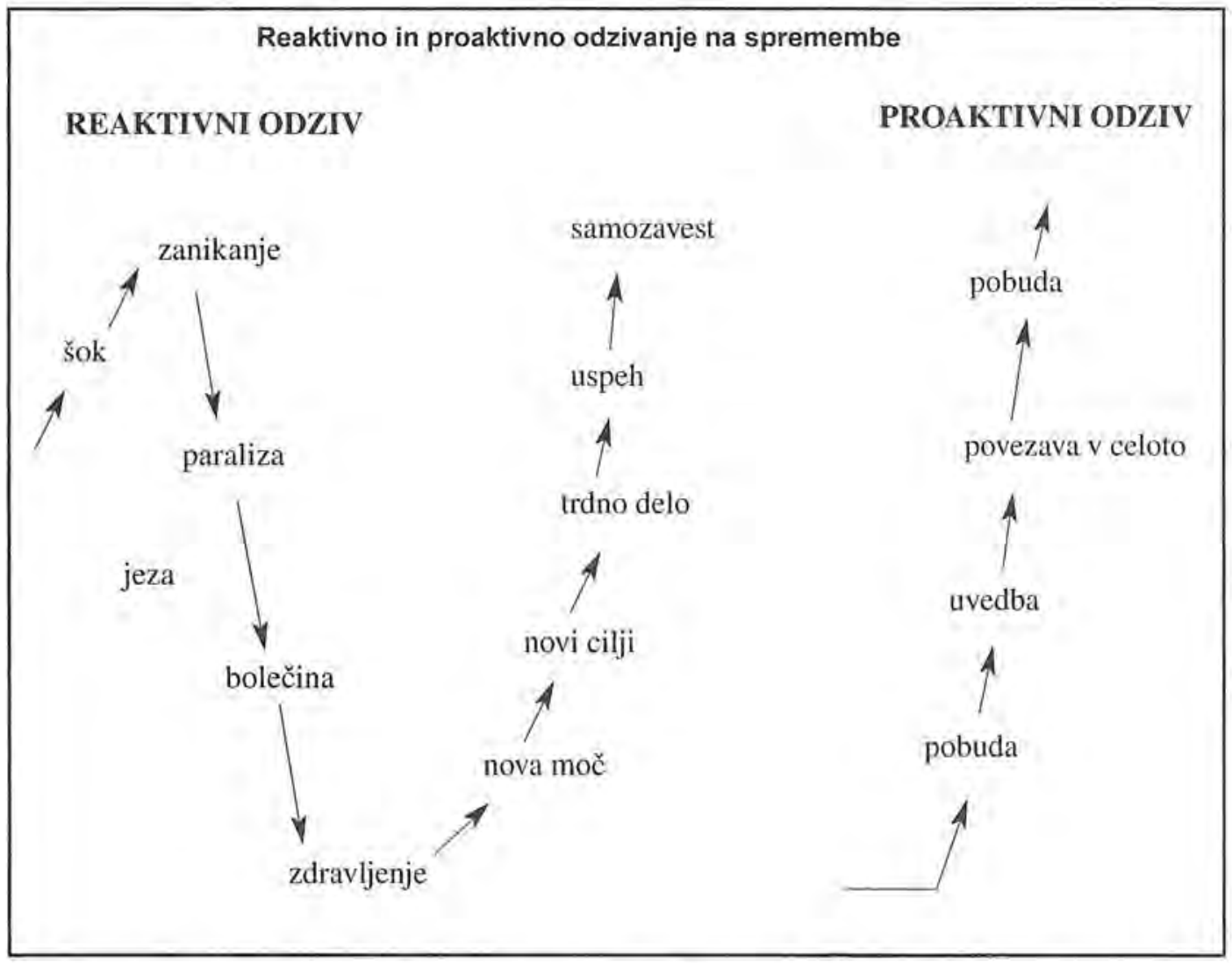

Nato potonejo $v$ cel niz neugodnih čustev jeze, žalosti, depresije itd., potem spremembo končno sprejmejo in se začnejo nanjo odzivati. Toda pred ustreznim odzivom si morajo znovā nabrati moči, ki so jo v nizu neugodnih čustev zapravili. Postaviti si morajo nove cilje in trdo delati, da znova doživijo uspeh. Ob tem potrebujejo obilico novega znanja, ob katerem se počasi vzpenjajo po krivulji učenja.

Za ljudi, ki na spremembo proaktivno reagirajo, pa bi lahko rekli, da delujejo $\mathrm{v}$ skladu s konceptom nenehnih izboljšav in se hitro vzpenjajo po krivulji učenja. To so ljudje, ki najpogosteje sami povzročajo spremembe. Takoj zatem pa že predvidijo prihodnji izziv oziroma priložnost in tudi vedo, kaj jim je v dani situaciji napraviti. Hitro se lotijo uvajanja spremembe in spremembo integrirajo v obliki novih navad, vedenj, spo- sobnosti. Krivulja učenja je izrazito strma in to jim omogoča, da kmalu zatem začnejo zopet s pobudo za spremembo.

Učinkovitega načrtovanja kariere si pravzaprav ni moč zamisliti v odsotnosti proaktivnega odzivanja na spremembe, še posebej če se zavedamo, da je fleksibilnost $\mathrm{v}$ globalni ekonomiji pravzaprav paradigma obstoja.

\section{POTREBUJEMO IZOBRAŽEVANJE ZA NAČRTOVANIE KARIERE?}

Odgovor je vsekakor pritrdilen. Ne glede na to, ali izbiramo prvi poklic ali se odločamo za karierni premik, potrebujemo za dober karierni načrt obilico novih znanj. Potrebo po učenju pri načrtovanju kariere bi zlahka primerjali z našim zdravstvenim stanjem. $\mathrm{Na}$ srečo smo ljudje večino časa zdravi, prav tako pa se ljudje na srečo večino časa tudi učimo. 
Učimo se iz vsakodnevnih situacij, od prijateljev, znancev, iz tujih izkušenj, preberemo pouěno zgodbo $v$ časopisu, gledamo dokumentarno TV oddajo. Viri za učenje še nikoli niso bili tako bogati in tako dostopni kot danes. Toda ravno tako kot moramo včasih $\mathrm{k}$ zdravniku, da ohranimo svoje zdravje, se moramo pri reševanju kariernih izzivov občasno zateči tudi $k$ bolj sistematičnim oblikam izobraževanja in diagnosticiranja kariernih priložnosti, še posebej kadar je problem velik ali pa se $\mathrm{z}$ določeno vrsto problema soočamo prvič. Šolsko učenje oz. formalni programi izobraževanja so lahko pomemben del tega učenja, vseeno pa $\mathrm{v}$ praksi predstavljajo le manjši del izobraževalnih aktivnosti za pripravo kariernega načrta. Vsekakor bi si želeli več pozornosti šolskega sistema pri razvoju veščin, ki jih potrebujemo za uspešno upravljanje kariere, toda svet dela se spreminja s tolikšno naglico, da po naravi okosteneli šolski sistemi ne morejo slediti tovrstnim potrebam.

\section{SAMOANALIZA OSEBNOSTI - KAKŠNA KARIERA JE ZAME NAJPRIMERNEIŠA?}

Pri konstruktivnem načrtovanju kariere je najbolj bistveno predvsem to, da posameznik dobro spozna svoje prednosti in pomanjkljivosti, meje in nevarnosti ter možne izzive in priložnosti. Samoanaliza osebnosti v povezavi z nadaljnjim kariernim razvojem bi morala dati jasno sliko osebnosti glede štirih temeljnih elementov:

\section{Prednosti}

Kakšne so moje prednosti?

Kje sem močan?

Kje sem že dosegel rezultate?

\section{Pomanjjkljivosti}

Kakšne so moje šibke strani?
Česa ne zmorem?

Kaj se moram še naučiti?

\section{Priložnosti}

Kje so moje priložnosti in izzivi?

Kaj mi predstavlja izziv?

Kakšne so moje vrednote?

\section{Nevarnosti}

Kje so moje meje?

Kakšne nevarnosti prežijo name?

Kaj se lahko zgodi, če sprejmem določeno rešitev?

Gre pravzaprav za klasično analizo SWOT analizo prednosti in pomanjkljivosti, priložnosti in nevarnosti (strengths, weaknesses, opportunities, threats).

Če si analizo SWOT podrobneje ogledamo, zlahka opazimo, da se vsi elementi nanašajo na samouvid, torej na samopoznavanje lastne osebnosti. Še zlasti prva dva, kar pa se tiče priložnosti in nevarnosti, moramo vsekakor poznati tudi trenutno situacijo na trgu dela in dinamiko ter zakonitosti določenih organizacijskih vlog (poklicev) ter Učni viri za konstruktivno načrtovanje kariere še nikoli niso bili tako bogati in tako dostopni kot danes. narave dela.

\section{ALI JE OBJEKTIVNA SLIKA O LASTNI OSEBNOSTI MOGOČA?}

Kadarkoli ocenjujemo sebe, smo seveda nujno subjektivni, saj se presojamo z lastnimi očmi in velikokrat $v$ lastni oceni izrazimo tisto, kar želimo biti v očeh drugih. Prav zaradi subjektivizma pri samocenjevanju kariernega potenciala so se $v$ praksi razvili mnogi instrumenti, ki pomagajo posamezniku pri-

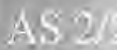


Napovedovanje prihodnosti je skorajda podobno vedeževanju, toda $\mathrm{k}$ načrtovanju kariere je vsekakor mogoče pristopiti sistematično in konstruktivno, in sicer skozi ovrednotenje intelektualnega, emocionalnega in socialnega kapitala posameznika.

dobiti objektivni vpogled $v$ lastne sposobnosti. Med njimi velja omeniti Center za ugotavljanje in merjenje kompetenc ali pod angleškim izrazom poznane assessment centre. Pri tem je treba še posebej poudariti, da so kompetence razumljene kot znanja, veščine, vrednosti in prepričanja posameznika, torej vse tisto, kar nekomu omogoča, da določeno delo dobro opravi, in ne morebiti kot pristojnosti, kar se velikokrat napačno prevaja v slovenski jezik.

In kaj ponujajo Centri za merjenje kompetenc, ki jih imamo nekaj tudi že v Sloveniji?

Center za merjenje in razvoj kompetence preko različnih ocenjevalnih testov in vprašalnikov zagotavlja posameznikom (in organizacijam) povratno informacijo o njihovi učinkovitosti, še posebej na področju vedenjskih kompetenc, življenjskih usmeritev in vrednot, reševanja problemskih situacij, timskih vlog, stilov vodenja ... Posameznik

\section{Nastavimo si} zrcalo. lahko tako na strokoven, hiter in anonimen način ugotovi svoje prednosti in omejitve. Večina vprašalnikov je oblikovanih po metodi 360 stopinj, kar zagotavlja visoko objektivno povratne informacije, še posebej kadar ocenjujemo posameznikove osebnostne poteze. To pomeni, da se posameznik oceni najprej sam, nato pa ga ocenijo še njegovi poklicni ali študijski kolegi, če gre za osebo, ki šele začenja svojo delovno kariero. Praviloma mora biti najmanj 5 ocenjevalcev poleg osebe, ki se samoocenjuje. Č gre za posameznika, ki je že aktivno vključen v delovno okolje, podajo oceno njegovi nadrejeni, sodelavci na isti ravni ter podrejeni. Tako pridobljena skupna ocena po metodi 360 stopinj ima nekaj izrazitih prednosti, še zlasti pri zagotavljanju visoke stopnje objektivnosti. Poleg tega ima posameznik priložnost spoznati, kako ocenjuje svoje prednosti in slabosti ter lastno predstavo o sebi $v$ primerjavi s predstavami drugih. Nemalokrat se izkaže, da je oseba premalo ali pa preveč samokritična. Z drugimi besedami rečeno, si s pomočjo metode 360 stopinj dobesedno nastavi zrcalo.

Ponavadi so vprašalniki podprti $\mathrm{z}$ računalniškimi programi, kar omogoča enostavno uporabo centra in hitro povratno informacijo. Uporabniki dobijo svoje osebno geslo in $\mathrm{z}$ njim lahko dostopajo na varnostno zaščiteno spletno stran, kjer izpolnjujejo vprašalnike. Ocenjevanje je popolnoma anonimno. V primeru uporabe metode 360 stopinj lahko uporabnik storitve sam določi soocenjevalce. Ocene soocenjevalcev so vidne, ni pa razkrito, kdo je kako ocenjeval. Ko uporabniki izpolnijo vprašalnik (samoocena ali po metodi 360 stopinj), v nekaj dneh prejmejo analizo $s$ priporočeno pošto na želeni naslov.

Tovrstni centri se najpogosteje uporabljajo:

- za osebnostni razvoj in individualno svetovanje

- za načrtovanje izobraževanja v podjetju

- za spodbujanje in razvoj timskega dela

- za upravljanje učinkovitosti

- za načrtovanje strateškega in organizacijskega razvoja

- za vrednotenje učinkov izobraževanja in usposabljanja ,.,.,

torej za večino dejavnosti, ki tvorijo tudi elemente konstruktivnega načrtovanja osebne kariere. 
Pridobljene rezultate seveda skrbno preučimo in iz njih moramo znati razbrati, ali je razkorak med našimi dejanskimi sposobnostmi, znanji, veščinami, vrednotami, torej $\mathrm{z}$ eno besedo kompetencami, ki jih posedujemo, in kompetencami, ki se zahtevajo za opravljanje določenega dela. In če razkorak je, kolikšen je in kako bi ga lahko zapolnili?

\section{MOST MED REALNOSTJO IN ŽELJAMI VODI PREKO UČENIA}

Razkorak ali manko praviloma lahko zapolnimo le tako, da si določeno sposobnost ali veščino razvijemo, si pridobimo novo znanje, torej vselej s trdim delom - učenjem.

Veliko je teorij in pristopov $\mathrm{k}$ učenju, ki jih priporočajo različni strokovnjaki. Toda le malo je univerzalnih resnic o učenju. Kako učinkovito se bomo učili, je odvisno od velikega števila dejavnikov, na primer od tipa naše osebnosti, situacije, $v$ kateri smo se znašli, od vsebine, ki naj bi se jo naučili, od preteklih izkušenj, naše motivacije za učenje ... Prav tako se vsi ljudje poslužujemo različnih vrst učnih procesov, pristopov, od katerih se nekáterih niti zavedamo ne in torej potekajo na nezavedni ravni. Vsekakor pa drži dejstvo, da več ko vemo o učenju, več uěnih pristopov in modelov poznamo, boljšo učno strategijo bomo lahko izbrali in dobro izrabili različne učne priložnosti, ki se nam ponujajo pri načrtovanju kariere. Najprej bomo našteli nekaj najpogosteje uporabljenih sistematičnih in načrtovanih učnih priložnosti, ki jih lahko izrabi posameznik pri načrtovanju svoje karierne poti. Nekatere izobraževalne poti na nek način ponujajo tudi del rešitev, ki jih sicer veliko bolj sistematično nudijo centri za ugotavljanje kompetenc, drugi pa so lahko le njihova nadgradnja. $\mathrm{V}$ nadaljevanju naštevam najpogostejše:

- Tečaji in seminarji za načrtovanje osebne kariere predstavljajo izobraževalne dogodke, pri katerih se uporablja cela vrsta različnih metod $\mathrm{z}$ namenom prepoznavanja lastnih kariernih ambicij. Tovrstne seminarje in tečaje organizirajo zavodi za zaposlovanje, razna združenja, študentske organizacije in poslovne šole.

- Mentorstvo: proces, pri katerem vam oseba $\mathrm{z}$ več izkušnjami namenja posebno pozornost in vam pomaga $\mathrm{z}$ nasveti in lastnimi delovnimi in življenjskimi izkušnjami. Pri tem je potrebno povedati, da je tovrstna oblika, ki je bila pred leti zelo moěno razširjena $v$ Sloveniji, v zadnjih nekaj letih skorajda izginila. Večina iskalcev zaposlitve postavlja mentorstvo na zelo visoko mesto pomembnosti, toda $\mathrm{v}$ praksi se je izkazalo, da sta

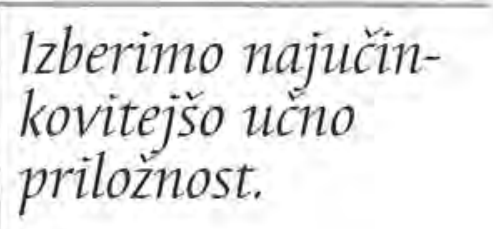
$\checkmark$ Evropi v povprečju le dva od petih novo zaposlenih deležna mentorstva. (Varey, str. 109) Treba je poudariti, da morajo imeti mentorji posebna znanja za izvajanje mentorskega procesa in si predvsem vzeti čas za mentorstvo. Mentorstvo seveda obravnavam veliko širše kot le pomoč novincem. Razumem ga kot nujno potrebni proces ne le za začetno uvajanje v delo vseh, ki še nimajo delovnih izkušenj, temveč tudi kot nujno potrebni prilagoditveni proces za vse, ki zamenjajo delovno mesto znotraj organizacije ali zamenjajo organizacijo.

- "Coaching" je proces osebnega svetovanja pri razvoju posebnih sposobnosti ali pri reševanju konkretnega problema. V zadnjem času se "coaching" poudarja kot ključna lastnost dobrih vodij, ki morajo nuditi pomoě zaposlenim v obliki osebne učne pomoči in biti torej $v$ vlogi svetovalca. Sama sem v vlogi vodje velikokrat v situaciji, ko me sodelavei prosijo za nasvet glede njihove nadaljnje kariere. Pri upravljanju osebne kariere imate torej vselej tudi 


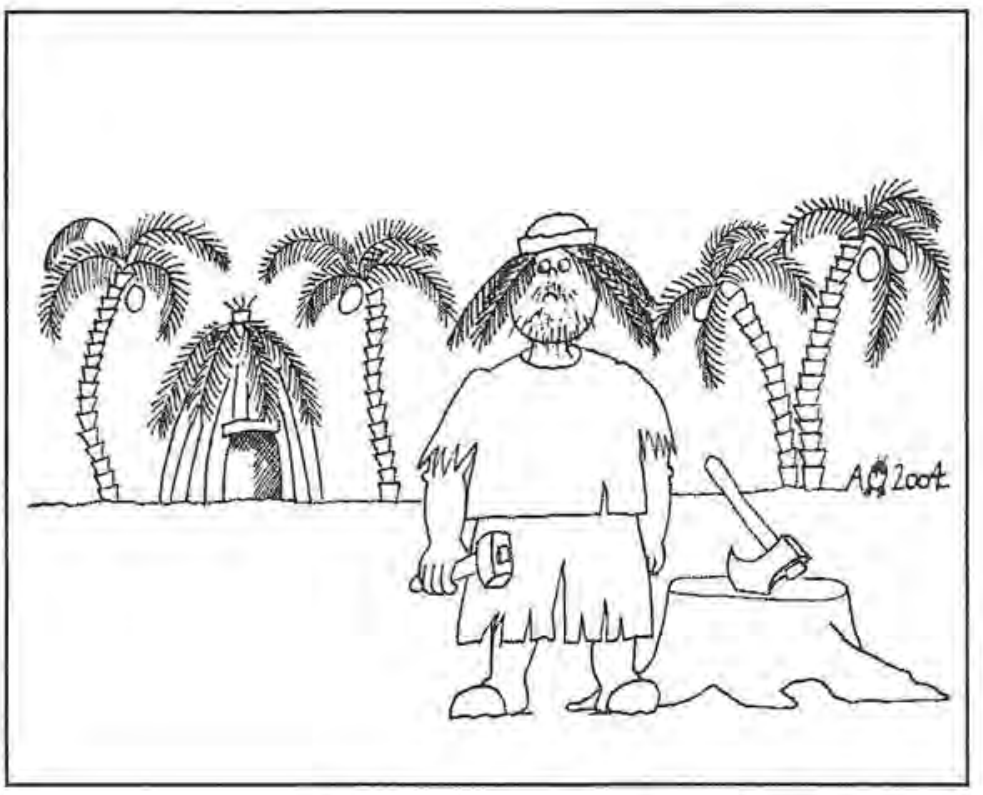

možnost, da poprosite vodjo za pomoč.

- E-učenje: v zadnjem času so se zelo razŠirili različni izobraževalni programi, ki so dostopni preko interneta. Prav tako vse več organizacij za svoje zaposlene uporablja sisteme e-učenja. Večina uvajalnih progràmov $v$ razvitejših organizacijăh je dostopnih v obliki e-učenja. Prednosti te uěne priložnosti so zagotovo dostopnost,

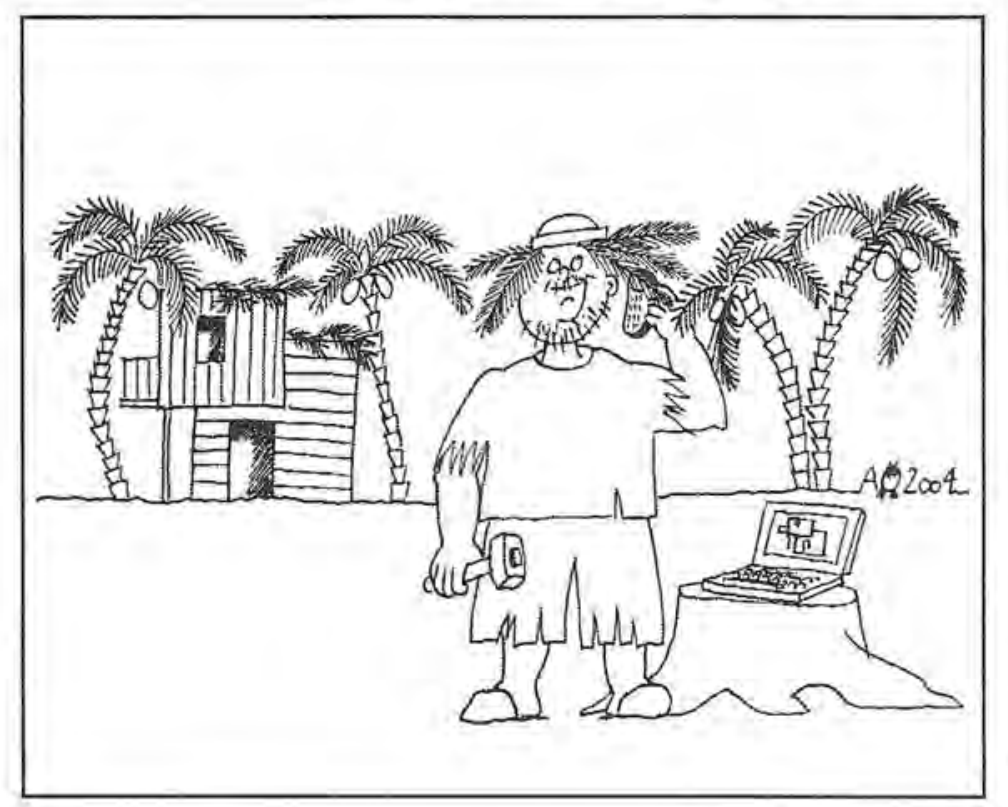

časovna in lokacijska neodvisnost, možnost osebnega načrtovanja učnega procesa ... Slabost pa je predvsem v okrnjeni socialni interakciji in pomanjkanju možnosti za neposredno izmenjavo mnenj ter izkušenj. Prav tako e-učenje zahteva večjo samodisciplino in trdno motivacijo.

- Borza znanja: svoje znanje z drugo osebo (brezplačno) izmenjamo za znanje, ki ga potrebujemo sami. Borze znanja so $v$ Sloveniji kar dobro razvite, vsekakor pa lahko zatrdim, da so kot učna priložnost za načrtovanje kariere še vse premalo izkoriščene. Ljudje preprosto ne pomislijo, da bi si lahko tudi na ta način pomagali pri načrtovanju kariere.

- Akcijsko učenje: učenje poteka v delovni situaciji, praviloma v manjših skupinah s ciljem kar največ naučiti se ob delu, tako da opazujemo posledice našega dela, razmišljamo, zakaj smo se lotili takšne in ne drugačne poti reševanja problema, in s pomočjo izmenjave mnenj ter izkušenj s kolegi v skupini.

- Samostojno učenje po načelu učne pogodbe: predstaylja idejo, da si posameznik sam postavi strukturo učnega procesa, pri čemer sam določi cilje, učne vire in strategije, rezultate ter kriterije za evalvacijo učnega procesa (Ǔ̃na pogodba je bila podrobneje predstavljena v reviji $A S$, št. 2/2002).

- "Senčenje": gre za opazovanje in pogovor z izkušenim posameznikom pri opravljanju dela, ki bi se ga želeli tudi sami naučiti.

- Videoteke in knjižnice: veliko organizacij ima lastne knjižnice in interaktivne videoteke, kjer je izbira virov za učenje zelo pestra in ponuja posamezniku tudi povratno informacijo.

- Osebno svetovanje: zaradi vse hitrejših sprememb se osebno svetovanje vse pogosteje uporablja. Gre za preprost način pomoči v tistem hipu, ko jo rabimo. Ko 
naletimo na problem ali novo situacijo, pokličemo osebnega svetovalca, ki nam na primer razloži nova organizacijska pravila ali pa rokovanje $\mathrm{s}$ paketom programske opreme ...

- Študije primerov: resnični primeri in opisi reševanja delovnih problemov, ki jih lahko pridobimo v obliki tekstov.

- Ekskurzije in obiski drugih organizacij, ki jih lahko primerjamo z "živim" študijem primera.

- Kritični dogodki: preučevanje kritičnih dogodkov posameznika na delovnem mestu, zapis teh dogodkov in pogovor o njih. Kritični dogodki so lahko tako pozitivni kot tudi negativni, torej tisti, ki izstopajo pri delu posameznika $v$ pozitivni ali negativni smeri.

- Simulacije in poslovne igre: posameznik lahko opazuje posledice, ki bi se lahko zgodile v realnem delovanju, le da zanje na ta način ni potrebno odgovarjati.

- Preizkušanje različnih organizacijskih vlog (job rotation): je odlična priložnost, da spoznamo, kakšno delo nam bolj leži, kje doživljamo posebno zadovoljstvo, česa nas je strah in česa ne maramo, kje so naši izzivi v organizaciji. Nekatere organizacije novincem omogočajo, da krožijo od enega do drugega delovnega mesta, dokler ne spoznajo celotnega delovnega procesa organizacije. Žal to omogoča vse manj organizacij, ker zahteva čas in aktivnost mentorjev.

Našteli smo le nekaj učnih priložnosti za sistematično načrtovanje kariere, ki se lahko uporabljajo tako za začetno načrtovanje kariere kakor tudi za vse kasnejše karierne premike. Nekatere oblike so bolj namenjene samoanalizi, druge lahko neposredno služijo premagovanju razkoraka in odpravi manka, ki je potreben za izbrani karierni premik.
Zgoraj naštete metode so tako rekoč "železni repertoar" učnih priložnosti za konstruktivno načrtovanje kariere.

\section{ALTERNATIVNE UČNE PRILOŽNOSTI ZA NAČRTOVANIE KARIERE}

Bolj ko postaja delo raznovrstno in posamezniki v svoje roke prevzemajo odgovornost za načrtovanje svoje osebne kariere, več izzivov, ki jih ponuja delovno okolje in globalno povezovanje $v$ celoti, bolj prihajajo do izraza tudi alternativne učne priložnosti za načrtovanja kariera. Oglejmo si jih nekaj.

\section{Organizacijske spremembe kot priložnost za (nov) začetek}

Večina aktivnega prebivalstva, torej ljudi, ki so $v$ aktivnem delovnem razmerju, gleda na organizacijske spremembe kot na potencialno nevarnost, da bodo izgubili delovno mesto. Toda, ali je ta pogled res vselej upravičen? Vsekakor vsakršna organizacijska sprememba nosi s seboj tudi določeno negotovost. Vsak človek se pri sebi sprašuje, ali bo še zmogel korak s časom, se bo uspel prilagoditi novim zahtevam, bo še konkurenčen na trgu delovne sile ... Tovrstna vprašanja si resda zastavljajo ljudje, ki imajo že nekajletne izkušnje s profesionalno oz, delovno kariero. Toda ne le ti, tudi čedalje več mladih, ki šele vstopajo na trg delovne sile, si zastavlja podobna vprašanja, morda le $\mathrm{v}$ nekoliko drugačni obliki: Ali si res želim tovrstno delo? Ali bom moral ob upoštevanju novih zahtev zanikati svoje vrednote, ali bom moral izbirati med delovno kariero in zasebnim življenjem ...? Vsekakor z napovedanimi organizacijskimi spremembami nastopi tudi vrsta bojazni, negotovosti, odprtih vprašanj ..., ki vsa zahtevajo odgovor na temeljno vprašanje: Ali bo sprememba pozitivno vplivala name, bom dobil novo priložnost, bom tej priložnosti kos ...? 
Narava mojega dela je takšna, da imam priložnost slišati in zabeležiti veliko mnenj glede (ne)gotove karirerne prihodnosti in žal moram navesti dejstvo, da se Negotovost se lahko spremeni $\mathrm{v}$ veliko priložnost. ljudje večinoma bojijo organizacijskih sprememb in jih zaznavajo pretežno kot instrument racionalizacije oz. zmanjševanja števila zaposlenih, kar navsezadnje pomeni, da imajo okrnjene možnosti konstruktivnega načrtovanja kariere.

Sama osebno vidim v organizacijskih spremembah veliko priložnost za karierne premike in napredovanja ter karierno rast posameznikov. Kot menedžer si ne bi želela ničesar bolj kot osebnih kariernih razvojnih načrtov posameznikov, ki bi jih bilo morda bolje na tem mestu poimenovati karierne ambicije. S preprostimi besedami bi to pomenilo, da bi bila menedžerska vloga, njegove odgovornosti in pristojnosti veliko lažji, če bi zaposleni ob reorganizacijah, ki so dandanes stalnica, znali razmisliti o svoji bodoči vlogi in predlagati menedžmentu, kje vidijo svojo bodočo vlogo, kako bi torej lahko doprinesli $\mathrm{k}$ razvoju in rasti organizacije. To bi po mojem strokovnem mnenju šele zares pomenilo, da je posameznik pripravljen prevzeti vso osebno odgovornost za načrto-

Potovanje kot beg od rutine in priložnost za poglobljeni reflektivni razmislek. vanje kariere. Žal pa je v praksi velikokrat ravno nasprotno.

Posebej želim poudariti, da so lahko napovedane ali nenapovedane organizacijske spremembe izvrstna priložnost za konstruktivno in samoodgovorno načrtovanje kariere, kar pa od posameznika zahteva visoko stopnjo samouvida, torej poznavanja svojih prednosti in pomanjkljivosti, prav tako pa tudi veliko sposobnost predvidevanja prihodnosti, torej vedenja o tem, v katerih
Ljudje še vedno pričakujejo in potrpežljivo čakajo, da bo za njihovo preživetje oz. kariero poskrbela organizacija. Toda v dobi dnevnih sprememb bo očitno paradigma organizacijske skrbi za zaposlene klavrno propadla in bo prevladala filozofija osebne odgovornosti na vseh področjih življenja, torej tudi na področju skrbi za karierni razvoj.

dejavnostih se skrivajo poslovne priložnosti jutrišnjega dne.

Pa tudi to še ni dovolj. Prav tako je treba dodobra poznati svoj vrednostni sistem, kajti vse bolj se utrjuje znanstveno prepričanje, da je uspeh ali neuspeh posameznika $v$ delovnem življenju odvisen od skladnosti dela, ki ga opravlja, z njegovim splošnim sistemom vrednot in prepričanj ter s svetovnim nazorom. Organizacijske spremembe lahko torej spremenimo $\mathrm{v}$ priložnosti za konstruktivno načrtovanje kariere, če le imamo dovolj znanja in samozavesti, da prepoznamo točko organizacijskih sprememb kot priložnost za naš osebni karierni premik.

\section{Na potovanje po svežo energijo za karierni razvoj}

Veliko mladih ljudi si pred redno zaposlitvijo "privošči" daljše potovanje po svetu, ali odidejo na delovne počitnice $v$ tujino, kjer se poslužujejo priložnostnih del, da zaslužijo za najnujnejše. Tudi ljudje, ki menjujejo poklic, delodajalca ali pa so preprosto "izgoreli" v določenem poklicu, se radi odpravijo po svežo energijo na potovanje. Potovanje jim omogoča beg od vsakdanje rutine in večjo možnost, da bodo počeli nekaj povsem drugega. Potovanje predstavlja bogat vir za načrtovanje kariere, saj se ponavadi srečamo z drugimi kulturami, drugimi vrednotami, kar v nas vzpodbudi procese razmišljanja in nam odpira nove horizonte mogočega. Niso 
redki tudi primeri, ko ljudje namenoma iščejo takšne zaposlitve, ki jim omogočajo veliko potovanj.

Vsekakor pa pomeni iskanje priložnostnih del na razliěnih destinacijah sveta iskanje kariernega sidra, lastne karierne usmeritve, čeravno si ljudje najprej izberejo kraj potovanja in šele potem iščejo delo. Računalniški programer iz Nemčije se na primer odloči preživeti tri mesece $v$ Turčiji in se zato, da ostaja materialno mobilen, odloči, da bo delal $v$ restavraciji. Takšne karierne izkušnje imajo lahko veliko skrito vrednost: razvijajo fleksibilnost, raznovrstne sposobnosti in veščine, samozavest in podjetnost - pravzaprav vse karakteristike, potrebne za preživetje $v$ novi globalni ekonomiji. Potovanja $v$ neznano imajo torej bogat učni potencial, ki pa se pogosto aktivira šele v retrospektivi - ko se torej posameznik odloči preusmeriti svojo kariero, bodisi zamenjati službo, začeti samostojno kariero bodisi vstopiti na trg dela. Na potovanjih pridobljene izkušnje so osnova za razvoj vrednot in s tem tudi trdnega kariernega vzorca. Nekdo, ki se je moral znajti $\vee$ neznani deželi, je zelo razvil samozavest, ki mu je pomagala najti tudi novo karierno usmeritev - odločitev za samostojno kariero.

\section{Materinstvo kot tranzicijsko obdobje}

Posebno obdobje in hkrati priložnost za reflektivni razmislek o karieri zagotovo predstavlja materinstvo. Veliko žensk v tem obdobju radikalno spremeni svoje videnje kariere in hkrati tudi osebne vrednote. Po prihodu s porodniškega dopusta so delodajalci čestokrat soočeni z željami glede povsem nove karierne usmeritve, kar pomeni, da je mlada mamica v tem času razmislila, kaj bi jo v prihodnosti veselilo delati in kako bi lahko čim bolje uravnotežila zasebno in poklicno življenje. Nemalo primerov je, ko so
Ženske porodniški dopust izkoristile tudi za dodatno izobraževanje in pridobitev tistih znanj, ki jih bodo potrebovale pri svojih nadaljnjih kariernih željah. Vsekakor pa je tudi kar nekaj primerov, ko so ženske popolnoma zamenjale poklic, ker so $v$ tem obdobju odkrile, da bi rade delale nekaj povsem drugega. Že $v$ času porodniškega dopusta so začele graditi vzporedno kariero in v tem času spoznale, da je prejšnja smer kariere postala neustrezna. V zadnjem času pa je moč zaslediti tudi veliko odločitev mladih mamic za samostojno karierno pot; odločijo se, da bodo odprle svoje podjetje, ker lahko tako bolje uravnotežijo potrebe zasebnega in poklicnega življenja. Večina

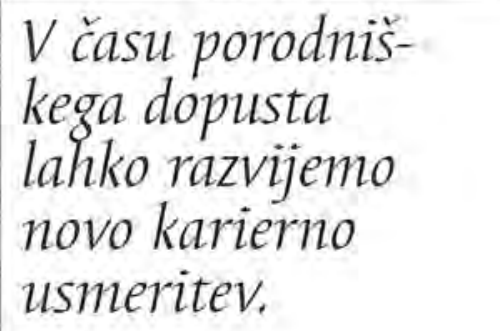
mamic si ne želi povsem izstopiti iz dela $\mathrm{V}$ času porodniškega dopusta, saj se zavedajo, da so spremembe tako silne, da bi imele ob vrnitvi na delo velike težave $\mathrm{z}$ učenjem in osvajanjem novosti. Delo namreč v obdobju enega leta lahko popolnoma spremeni svoje lastnosti, kar od posameznika zahteva tudi novo karierno usmeritev. Kar precej primerov je torej tudi takšnih, ko mlade mamice delajo doma naloge in dela, ki so jih opravljale tudi predhodno, in se razvijajo skupaj z njimi ter tako aktivno usmerjajo svoj karierni razvoj tudi $v$ času porodniškega dopusta. Tako niso redki primeri, ko mlade mamice po vrnitvi s porodniškega dopusta napredujejo na bolje plačano ali bolj ugledno delovno mesto, Vsekakor je na tem mestu potrebno omeniti tudi nevarnost, da mlade mamice delo pri delodajalcu ne bo več čakalo. Toda to nevarnost drastično zmanjšamo ravno $\mathrm{z}$ aktivnim razmišljanjem o naši bodoči karierni usmeritvi in seveda tudi s posameznimi aktivnostmi, ki jih vidimo kot nujne na poti do našega novega kariernega cilja. 


\section{ZAKLJUČNE MISLI}

Za konstruktivno upravljanje življenjskih na$\log$ je torej potrebno najprej določiti resnični problem, lastne reakcije nanj in lastna občutja, na problem primerno odgovoriti, torej izbrati primeren odziv, in oceniti posledice našega odgovora na problem. Upravljanje življenjskih nalog, kamor sodi tudi skrb za načrtovanje in upravljanje kariere, je torej največja življenjska naloga nasploh, saj se bo na obzorju vedno pokazal nov problem ali nova življenjska naloga, bodisi da imamo $v$ mislih biosocialni, družinski ali karierni cikel posameznika. Pri tem se je izkazalo, da so medosebni odnosi zelo pomembni, saj za reševanje problemov potrebujemo druge ljudi, potrebujemo nove ideje, poglede, čustveno podporo. Posameznik lahko raste in zori le v socialno bogati klimi. Ena izmed pomembnih veščin konstruktivnega upravljanja kariere je potemtakem tudi sposobnost vzpostavljanja bogatih medosebnih odnosov z drugimi. Tako bomo uspeli ohraniti proaktivni pristop $\mathrm{k}$ upravljanju sprememb in med bogatimi učnimi viri uspeli izbrati najučinkovitejšo učno strategijo, ki nam bo pomagala najti ustrezno karierno usmeritev ali pot.

\section{LITERATURA}

Arthur, B. M., Inkson, K., Pringle, J* K. (1999), The New Careers. Sage Publications.

Avery, R. (1960). Enculturation in Industrial Research. IRE Transactions on Engineering Management 7, str. 20-24.

Brečko, D. (1998). Kako se odrasli spreminjamo. Didakta.

Brečko, D. (2002). Pogovori z novozaposlenimi-zapisi. Ljubljana.

Brecko, D. (2004). Pogovori z ljudmi, ki so spremenili karierno usmeritev - zapisi. Ljubljana.

Brookfiled, S. D. (1986). Understanding and Facilitating Adult Learning. San Francisco: Jossey-bass.
MA: Kent.

Dalton, G. W, Thompson, P. H, in Price, R. (1977). Career Stage: A Model of Professional Careers in Organisations. Organisational Dynamics, Summer, str. 19-24.

Holton, E. F. (1998). Performance Domains: Bounding the Theory and Practice. Advances in Developing Human Resources. Washington, D. C. ISPI Press.

Knowles, M. S. (1980). The Modern Practice of Adult Education: From Pedagogy to Andragogy. Cambridge: Englewood Cliffs.

Knowles, M. S. (1984). Andragogy in Action. San Francisco: Jossey-Bass.

Pegg, M. (1990): Corporate change making it work. Lifeskills News, Lifeskills communication, Spring, str. 7.

Van Maanen, J. (1975). Breaking in: A Consideration of Organizational Socialization. V Dubin, R. (ur.). Handbook of Work, Organization and Society. Chicago: Rand-McNally.

Zunker, V. G. (1998), Career STH Counseling. Brooks/Cole Publishing Company. 